\title{
Evaluation of Oxidative Stress on Soybean (Glycine max L. Merrill) and Wheat (Triticum aestivum) Crops in Response to Chlorpyrifos
}

\author{
Nutan Singh ${ }^{*}$, Pratibha Katiyar and Ajay \\ Department of Plant Physiology, Indira Gandhi Krishi Viswavidyalaya, \\ Raipur-492012, Chhatishgarh, India \\ *Corresponding author
}

\author{
A B S T R A C T
}

\begin{tabular}{|l|}
\hline Ke y w o r d s \\
Oxidative stress on \\
soybean, Wheat, \\
Crops.
\end{tabular}

\section{Introduction}

The use of synthetic pesticides as crop protection chemicals has become the most accepted ecological weapon for assured crop production. With the restricted use of most of the organochlorine insecticides, the organophosphorus compounds are taking the major share of insecticide consumption in India (Aditya et al., 1997). Chlorpyrifos [O,Odiethyl $O$-(3,5,6-trichloro-2-pyridyl) phosphorothioate] is a broad-spectrum organophosphate insecticide being used for more than a decade to control foliar insects that affect agricultural crops, to reduce pod damage (Khan et al., 2009, Kumar et al., 2010), and subterranean termites (Venkateswara Rao et al., 2005). Chlorpyrifos produces hazardous effects on the environment when it is applied directly on plants or mixed with soil (Howard 1991). Soybean (Glycine max L. Merrill) is an important pulse as well as oilseed crop. It has become wonder crop of twentieth century and is often designated as "Golden bean." And Wheat (Triticum spp.), the world's most 
widely cultivated crop, in 2000, world wheat production was approximately 572 million metric tons on 205 million hectares (Anonymous 2002, Stoskopf 1985). Wheat is the staple food for about $40 \%$ of the world's population (Wiese 1987). Common bread Wheat (T. aestivum, L.) and durum Wheat ( $T$. durum Desf.) make up 90\% of the world's Wheat crop. Wheat is further classified as winter or spring, hard or soft, red or white, and by protein content (Briggle and Curtis 1987). In the process of development of agriculture, pesticides have become an important tool as a plant protection agent for boosting food production.

\section{Materials and Methods}

A pot experiment will be laid out in control condition in completely Randomized Block Design at Indian Institute of soil science, Bhopal. Lab work will be conducted in laboratory of Indian Institute of Soil Science.

Description of crop: Soybean and Wheat Soybean genotype: JS 9305

Wheat genotype: HD 2987

Physiological parameters were measured using standard procedures. The following parameters were studied in the present study.

\section{Morphological parameters}

\section{Plant height}

Plant height was recorded from base of the plant to the uppermost node of main shoot of plant at 30 days after showing (DAS) and 45 days (DAS) and 60 days (DAS). In each site, one plant was selected and height was expressed in $\mathrm{cm}$.

\section{Plant biomass}

The selected plant was removed from the plastic container. The whole plant was divided into leaves, stem and roots and then weight of leaves and stem was measured for fresh weight. The samples were dried in oven for $72 \mathrm{hrs}$ at $65^{\circ} \mathrm{C}$ and total dry weight (expressed in gram) of leaves and stem was recorded for dry weight.

\section{Root biomass}

The whole root was weighed immediately for fresh weight and dried in oven for $72 \mathrm{hrs}$ at $65^{\circ} \mathrm{C}$ and total dry weight (expressed in gram) of root was recorded for dry weight.

\section{Leaf area}

Leaf area was measured by leaf area meter LICOR make (Model 3100) and expressed in $\mathrm{cm}^{2}$.

\section{Physiological parameters}

$\begin{aligned} & \text { Estimation of gaseous exchange } \\ & \text { parameters }\end{aligned}$
aras

Gas exchange parameters viz. Photosynthesis rate $\left(\mu \mathrm{MCO}_{2} \mathrm{~m}^{-2} \mathrm{~s}^{-1}\right)$, transpiration rate $\left(\mathrm{MmH}_{2} \mathrm{O} \mathrm{m} \mathrm{m}^{-2} \mathrm{~s}^{-1}\right)$ and stomatal conductance $\left(\mu \mathrm{M} \mathrm{m}^{-2} \mathrm{~s}^{-1}\right)$ were recorded in the morning (9 to 11:30 AM) in the experimental plant leaves using Photosynthesis system (make: PP systems and model: CIRAS-3).

\section{Biochemical parameters}

Peroxidase (POX) activity assay ( $\triangle \mathrm{OD} \mu \mathrm{g}$ $\operatorname{protein}^{-1} \min ^{-1}$ )

POX activity was assayed by following the method of summer and Gjessing, (1943). The extract from SOD Assay was used for POX assay. Added $1 \mathrm{ml} \mathrm{O}$-dianisidine $(0.01 \mathrm{M}$ in methanol), $0.5 \mathrm{ml} \quad \mathrm{H}_{2} \mathrm{O}_{2} \quad(0.02 \mathrm{M}), 1 \mathrm{ml}$ phosphate buffer, $2.4 \mathrm{ml}$ distilled water and $0.2 \mathrm{ml}$ enzyme and incubated at $30^{\circ} \mathrm{C}$ for 5 $\mathrm{min}$. The reaction was stopped by adding $1 \mathrm{ml}$ $2 \mathrm{~N} \mathrm{H}_{2} \mathrm{SO}_{4}$. Blank tube excluding $\mathrm{H}_{2} \mathrm{O}_{2}$ was 
prepared by adding $0.5 \mathrm{ml}$ distilled water. The colour intensity was measured by spectrophotometer at $430 \mathrm{~nm}$ wavelength and POX was expressed in unit $\left(\Delta \mathrm{OD} \mu \mathrm{g}\right.$ protein $^{-1}$ $\left.\min ^{-1}\right)$.

\section{Estimation of nitrate reductase activity $\left(\mu \mathrm{gNO}_{2} / \mathrm{g} \mathrm{fw/h}\right)$}

Nitrate reductase can be estimated by the in vivo assay method given by Nicholas and Nason (1957), by incubating pieces of plant tissues as such in $\mathrm{KNO}_{3}$ solution. The amount of nitrite formed is estimated as a measure of the enzyme activity. Leaves were cut into 2$3 \mathrm{~mm}$ fragments and suspended in $5 \mathrm{ml}$ of phosphate buffer containing $0.1 \mathrm{M} \quad \mathrm{KNO}_{3}$ placed in $25 \mathrm{ml}$ beakers. The beakers were placed in a vacuum desiccator and tissues were vacuum infiltrated. The beakers were incubated in a water bath at $30^{\circ} \mathrm{C}$ for $30 \mathrm{~min}$. $2.5 \mathrm{ml}$ of sulphanilamide- $\mathrm{HCl}$ was added to estimate the nitrite formed in suspending medium.

The mixture was filtered through Whatman No.1 filter paper to remove the leaf fragments and $2.5 \mathrm{ml}$ of $\mathrm{NEDH}$ was added. The absorbance of solution was measured at 540 $\mathrm{nm}$ in a colorimeter. The results were expressed as $\mu \mathrm{mol} \mathrm{NO}_{2}$ - formed per $30 \mathrm{~min}$ per $g$ fresh tissue.

\section{Estimation of polyphenol oxidase $(\triangle O D \mu g$ protein $^{-1} \min ^{-1}$ )}

Polyphenol oxidase was measured by following method given by Fujita (1979).

0.2 M Acetate Buffer $\mathrm{pH} 4.5$

$0.2 \mathrm{M}$ phosphate buffer $\mathrm{pH} 6.0$

$1 \%$ pyrogallol solution

Acetate buffer: for 1 liter $=3.5 \mathrm{ml} \mathrm{CH}_{3} \mathrm{COOH}$ + 3.2g Sodium Acetate Phosphate Buffer: For 1 liter $=\mathrm{KH}_{2} \mathrm{PO}_{4} 11.93 \mathrm{~g}+\mathrm{K}_{2} \mathrm{HPO}_{4} 2.14 \mathrm{~g}$
Method: leaves sample $0.2 \mathrm{~g}+10 \mathrm{ml}$ acetate buffer $\rightarrow 10 \mathrm{~min}$ incubation. $1 \mathrm{ml}$ supernatant $2 \mathrm{ml}$ phosphate buffer $0.5 \mathrm{ml}$ pyrogallol $\rightarrow$ OD at $495 \mathrm{~nm}$.

\section{Total soluble protein assay}

Total soluble protein was measured by following method given by Bradford (1976). Used the extract for assay and added $0.2 \mathrm{ml}$ sample, $4 \mathrm{ml} 0.1 \%$ protein reagent $(100 \mathrm{mg}$ Coomassie Brilliant Blue) and $0.8 \mathrm{ml}$ distilled water. The colour intensity was measured by spectrophotometer at $595 \mathrm{~nm}$ wavelength. Calculation of the total soluble protein content was done by creating a standard curve using a standard bovine serum albumin (25 $\mathrm{mg}$ in $0.15 \mathrm{M} \mathrm{NaCl}$ and made up to volume $25 \mathrm{ml}$ stock and working stock was made by diluting 10 times) and was expressed in $\mathrm{mg}$ per gram fresh weight $\left(\mathrm{mg} \mathrm{g}^{-1} \mathrm{FW}\right)$.

\section{Estimation of non-structural carbohydrate (mg/g)}

Non-structural carbohydrate was calculated as sum of total soluble sugar and starch and expressed as percentage of dry weight.

\section{Estimation of proline content $\left(\mu \mathrm{mg}^{-1}\right)$}

Proline content was measured following the method of Bates et al., (1973). 0.5 gram of fresh plant sample (leaves) was taken and $10 \mathrm{ml}$ of $3 \%$ aqueous sulphosalicylic acid added and ground in pestle and mortar, and then filtered through whatman No. 42 filter paper.

\section{Statistical analysis}

CRD (Completely randomized design) was used to statistical analysis. The analysis was performed online in OPSTAT (Online statistical analysis tool) analysis. The critical difference (C.D.) was calculated at 5\% levels. 


\section{Results and Discussion}

\section{Morphological parameter}

\section{Plant height (cm)}

The plant height of soybean, and wheat were evaluated at 30 days, 45 days and 60 days after sowing the pesticide chlorpyrifos were sprayed (by Trigger type hand spryer) and having the nozzle (soild cone) one week before the observation recorded. Hence the oxidative stresses were applied three days in all experimental crops. It was observed that the plant heights were not affected significantly in all the experimental crops except in wheat at 60 DAS. However, the plant heights of all the experimental crops were higher in control (no chlorpyrifos). The plant height is decreased with increasing concentraiont of chlorpyrifos in soybean and wheat. However, there was non-significant variation within treatments (Table 1; Fig. 12).

The similar impact were observed by Kumar and Kumar (1993) in Vicia faba by the use of metasystox @50-100 mg/l. The higher concentration $200-300 \mathrm{mi} / 1$ were found to have inhibitory effect on plant height, no. of branches, no of leaves per plants, total leaf area and plant biomass. The similar results were confirmed by Bashir et al., (2007) in Lens culinaris L. with mancozeb. Stevens et al., (2008) in rice with use of imidacloprid. They observed the lower dose of dimethoate $(50 \mathrm{ppm})$ proved stimulant in growth of rice.

The suppression in morphological parameters might be due to the retarded cell growth and division in root, cell elongation and conversion of Indole-3- acetic acid IAA into various photooxidative products. Tevini and Teramura (1989) suggested that these compounds function as strong auxin antagonists. Another reason could be explained on the basis of inhibition in the activity of 4- hydroxyl phenyl pyruvate dioxygenase (HPPD), an enzyme needed for the growth and development of meristematic tissue as suggested by Luscombe et al., (1993) following pesticide isoxaflutole treatment in maize and sugarcane.

\section{Leaf area $\left(\mathrm{cm}^{2}\right)$}

Leaf area of experimental crops was significantly affected with chlorpyrifos doses. However, the maximum increase in leaf area was observed at lower dose of pesticide in wheat (41.66) over control (39.03) where as in soybean increased concentration of pesticide decreased the leaf area gradually (Table 2).

Kasyap and Kumar (2013) also reported that the lower concentration (50ppm) of chlorpyrifos significantly proved highly effective, non-phytotoxic and seemed to elevate growth parameters. Kumar and Kumar (1993) also confirmed the similar impact were observed by on Vicia faba by the use of metasystox@50-100 mg/l. The higher concentration 200-300mi/l were found to have inhibitory effect on plant height, no. of branches, no of leaves per plants, total leaf area and plant biomass.

\section{Leaf dry wt. (g)}

Significant impact of chlorpyrifos treatment was observed in dry weight of leaf in soybean and wheat at 30 and 60 DAS. The increased concentration significantly decreased the dry weight of leaves (Table 3 ).

Siddiqui et al., (1997) have reported that usage of low dosage of Methyl thiophenate (fungicide) treatment in Sesbania sesban has been found to cause an increase in fresh and dry weight, where higher dosages have been found to be deleterious. Though most of the 
systemic fungicides are used as seed dressing, yet there are several reports showing phytotoxicity on various plants. Similar facts were observed by Hack, 1994: Holderness, 1990; Kaspers et al., 1987).

\section{Stem dry weight (g)}

The stem dry weight was non-significantly affected by various concentration of chlorpyrifos treatment in soybean and wheat. However, it was effective at later phases of growth when applied hence in wheat increased concentration decreased the dry matter of stem gradually over control. This might be due to the control of pest infestation resulted more leaf area and better dry matter production. However, the response of higher dose was found negative due to higher oxidative stress automatically reduced the photosynthetic rate and resulting reduced dry matter partitioning and stem weight (Table 4).

Kumar and Kumar (1993) also confirmed the similar impact were observed by on Vicia faba by the use of metasystox @ 50-100 mg/l. The higher concentration $200-300 \mathrm{mi} / 1$ were found to have inhibitory effect on plant height, no. of branches, no of leaves per plants, total leaf area and plant biomass. Iqtidar et al., (1995) also confirmed the similar effect of morpholine systemic fungicide in wheat and maize plants. And Elbashir et al., (2016) also confirmed the sevin (carbaryl) recommended dose relatively had a positive effect on plant height, dry weight, and no. of leaves per plant.

\section{Root dry weight (g)}

The impact of pesticide treatment was observed on root dry weight of soybean and wheat At 30, 45 and 60 DAS. The root dry weight was significantly higher at control $(0.213)$ in soybean. The increased concentration of pesticide decreased the dry weight of root. The similar trend was observed in wheat also. However, at 60 DAS the difference in root dry was non-significant with increased rate of pesticide application. The might be due to the plant growth physiology. Plant attained maximum root growth upto that phase (Table 5).

Boutin et al., (2004) also reported that the phytotoxic and inhibitory effects of herbicides on germination, root and shoot growth. Basher et al., (2007) also confirmed the similar impact of seed treatment by mancozeb on various morphological parameters in Lens culinaris L. in different developmental stage and concluded that all the morphological parameters increased significantly only lower dose $(0.1 \%)$ whereas a liner decrease with increasing concentrations of mancozeb was observed.

\section{Photosynthesis rate $\left(\mu\right.$ mole $\left.\mathrm{CO}_{2} / \mathrm{m}^{2} / \mathrm{sec}\right)$}

The photosynthesis rate was measured in $3^{\text {rd }}$ fully expended leaves from the top. The rate was highest in control and gradually decreased with increase concentration of treatment. The mean value was greater in control (8.32) in soybean. Whereas in wheat the average value of photosynthesis rate was highest at $\mathrm{T}_{3} 0.75 \%$ of chlorpyrifos (9.28) followed by control (8.53) and at $\mathrm{T}_{1} 0.25 \%$ (7.58) the minimum photosynthesis rate was observed in $\mathrm{T}_{4} 1.25 \%$ concentration of chlorpyrifos (6.58). However, the result was non-significant at 30 DAS (Table 6; Fig. 3-4).

Decreased photosynthetic efficiency of the high concentration Chlorpyrifos treated seedlings may decrease the production of dry matter. The studies of Kumar et al., (1993) indicate that the use of Metasystox on Vicia $f a b a$ is promontory for seed germination and growth when used in lower concentrations (50-100 $\left.\mathrm{mg} \mathrm{l}^{-1}\right)$. The higher concentrations (200-300 $\mathrm{mg} \mathrm{l}^{-1}$ ) were inhibitory for 
photosynthesis rate stomatal conductance and transpiration rate. Similar results have been obtained by Coskun et al., (2015) in maize reported by Olszewski (2004) in pea and Singh et al., (1970) in Citrus.

\section{Stomatal conductance $\left(\mu \mathrm{mol} / \mathrm{m}^{2} / \mathrm{sec}\right)$}

Stomatal conductance was measured at 30,45 and 60 DAS at various concentration of pesticide. It was observed that the pesticide have significant impact on this physiological parameter of gaseous exchange. The stomatal conductance was increase with increased level of pesticide in soybean and wheat. In soybean maximum stomatal conductance was observed at $\mathrm{T}_{4} 1.25 \%$ treated (111.33) over control (100.00). Whereas, in wheat value was maximum in treatment $\mathrm{T}_{2} 0.25 \%$ (3.31) followed by $\mathrm{T}_{3} \quad 0.75 \%$ (3.09) and $\mathrm{T}_{4} \quad 1.25 \%$ (2.86). (Table 7).

Xia et al., (2006) also reported that the The phytotoxicities of nine pesticides at practical dosages on photosynthesis were investigated in cucumber (Cucumis sativus L.) Plants treated with paraquat showed the severest phytotoxic symptom with the highest reduction in net photosynthetic rate, stomatal conductance (Gs) and intercellular $\mathrm{CO}_{2}$ concentration (Ci). Dias M. C. (2012) also confirmed the similar impact of these compounds on the photosynthetic apparatus.

Table.1 Impact of pesticide on plant height $(\mathrm{cm})$ of soybean and wheat at various growth phases i.e., 30, 45 and 60 DAS

\begin{tabular}{|c|c|c|c|c|c|}
\hline Plant height $(\mathrm{cm})$ & $\begin{array}{c}\text { DAS } \\
\mathbf{3 0}\end{array}$ & $\begin{array}{c}\text { DAS } \\
45\end{array}$ & $\begin{array}{c}\text { DAS } \\
60\end{array}$ & Total & Mean \\
\hline \multicolumn{6}{|l|}{ Soybean } \\
\hline $\mathrm{T}_{1}-$ Control (No chlorpyrifos) & 27.00 & 28.50 & 31.00 & 86.50 & 28.83 \\
\hline $\mathrm{T}_{2}-0.25 \%$ (low) & 25.00 & 27.50 & 30.00 & 82.50 & 27.50 \\
\hline $\mathrm{T}_{3}-0.75 \%$ (medium) & 25.50 & 26.00 & 27.00 & 78.50 & 26.17 \\
\hline $\mathrm{T}_{4}-1.25 \%$ (High) & 23.50 & 24.50 & 26.00 & 74.00 & 24.67 \\
\hline Mean & 25.25 & 26.63 & 28.50 & & \\
\hline $\mathrm{CD}(\mathrm{P}=0.05)$ & NS & 1.75 & 3.49 & & \\
\hline $\mathrm{CD}(\mathrm{P}=0.01)$ & NS & NS & NS & & \\
\hline $\mathrm{SE}(\mathrm{m} \pm)$ & 0.79 & 0.43 & 0.87 & & \\
\hline C.V. & 4.43 & 2.30 & 4.30 & & \\
\hline \multicolumn{6}{|l|}{ Wheat } \\
\hline $\mathrm{T}_{1}$ - Control (No chlorpyrifos) & 44.00 & 61.00 & 68.00 & 173.00 & 57.67 \\
\hline $\mathrm{T}_{2-}-0.25 \%(\mathrm{low})$ & 37.00 & 59.00 & 62.50 & 158.50 & 52.83 \\
\hline $\mathrm{T}_{3}-0.75 \%$ (medium) & 40.50 & 54.00 & 67.00 & 161.50 & 53.83 \\
\hline $\mathrm{T}_{4}-1.25 \%$ (High) & 46.00 & 57.00 & 58.00 & 161.00 & 53.67 \\
\hline Mean & 41.88 & 57.75 & 63.88 & & \\
\hline $\mathrm{CD}(\mathrm{P}=0.05)$ & 5.79 & 4.03 & 3.02 & & \\
\hline $\mathrm{CD}(\mathrm{P}=0.01)$ & NS & NS & 4.88 & & \\
\hline $\mathrm{SE}(\mathrm{m} \pm)$ & 1.44 & 1.00 & 0.75 & & \\
\hline C.V. & 4.85 & 2.45 & 1.66 & & \\
\hline
\end{tabular}


Table.2 Impact of pesticide on leaf area $\left(\mathrm{cm}^{2}\right)$ of soybean and wheat at various growth phases i.e., 30, 45 and 60 DAS

\begin{tabular}{|c|c|c|c|c|c|}
\hline Leaf area $(\mathrm{cm} 2)$ & $\begin{array}{l}\text { DAS } \\
30 \\
\end{array}$ & DAS 45 & $\begin{array}{l}\text { DAS } \\
60 \\
\end{array}$ & Total & Mean \\
\hline \multicolumn{6}{|l|}{ Soybean } \\
\hline $\mathrm{T}_{1}$ - Control (No chlorpyrifos) & 118.60 & 153.26 & 204.76 & 476.61 & 158.87 \\
\hline $\mathrm{T}_{2^{-}} 0.25 \%$ (low) & 116.50 & 119.25 & 191.46 & 427.21 & 142.40 \\
\hline $\mathrm{T}_{3}-0.75 \%$ (medium) & 110.55 & 128.15 & 151.18 & 389.88 & 129.96 \\
\hline $\mathrm{T}_{4^{-}} 1.25 \%(\mathrm{High})$ & 104.38 & 114.35 & 153.00 & 371.73 & 123.91 \\
\hline Mean & $\mathbf{1 1 2 . 5 1}$ & $\mathbf{1 2 8 . 7 5}$ & $\mathbf{1 7 5 . 1 0}$ & & \\
\hline $\mathrm{CD}(\mathrm{P}=0.05)$ & 7.43 & 13.42 & 26.53 & & \\
\hline $\mathrm{CD}(\mathrm{P}=0.01)$ & NS & 21.66 & 42.83 & & \\
\hline $\mathrm{SE}(\mathrm{m} \pm)$ & 1.84 & 3.33 & 6.58 & & \\
\hline C.V. & 2.32 & 3.66 & 5.31 & & \\
\hline \multicolumn{6}{|l|}{ Wheat } \\
\hline $\mathrm{T}_{1}$ - Control (No chlorpyrifos) & 37.35 & 44.48 & 35.27 & 117.09 & 39.03 \\
\hline $\mathrm{T}_{2^{-}} 0.25 \%$ (low) & 33.88 & 34.63 & 56.46 & 124.97 & 41.66 \\
\hline $\mathrm{T}_{3^{-}} 0.75 \%$ (medium) & 29.60 & 31.50 & 37.32 & 98.41 & 32.80 \\
\hline $\mathrm{T}_{4^{-}}-1.25 \%(\mathrm{High})$ & 34.84 & 39.69 & 35.76 & 110.29 & 36.76 \\
\hline Mean & 33.92 & 37.57 & 41.20 & & \\
\hline $\mathrm{CD}(\mathrm{P}=0.05)$ & 4.67 & 4.57 & 6.06 & & \\
\hline $\mathrm{CD}(\mathrm{P}=0.01)$ & NS & 7.37 & 9.78 & & \\
\hline $\mathrm{SE}(\mathrm{m} \pm)$ & 1.16 & 1.13 & 1.50 & & \\
\hline C.V. & 4.83 & 4.26 & 5.16 & & \\
\hline
\end{tabular}

DAS (Days after sowing)

Table.3 Impact of pesticide on leaf dry weight $(\mathrm{g})$ of soybean and wheat at various growth phases i.e., 30, 45 and 60 DAS

\begin{tabular}{|c|c|c|c|c|c|}
\hline Leaf dry wt. (g) & $\begin{array}{c}\text { DAS } \\
\text { 30 }\end{array}$ & $\begin{array}{c}\text { DAS } \\
45\end{array}$ & $\begin{array}{c}\text { DAS } \\
60\end{array}$ & Total & Mean \\
\hline \multicolumn{6}{|l|}{ Soybean } \\
\hline $\mathrm{T}_{1}-$ Control (No chlorpyrifos) & 0.860 & 0.960 & 1.525 & 3.345 & 1.115 \\
\hline $\mathrm{T}_{2^{-}} 0.25 \%$ (low) & 0.650 & 0.855 & 1.120 & 2.625 & 0.875 \\
\hline $\mathrm{T}_{3^{-}} 0.75 \%$ (medium) & 0.580 & 0.780 & 0.960 & 2.320 & 0.773 \\
\hline $\mathrm{T}_{4^{-}}-1.25 \%(\mathrm{High})$ & 0.510 & 0.750 & 1.015 & 2.275 & 0.758 \\
\hline Mean & 0.650 & 0.836 & 1.155 & & \\
\hline $\mathrm{CD}(\mathrm{P}=0.05)$ & 0.144 & 0.086 & NS & & \\
\hline $\mathrm{CD}(\mathrm{P}=0.01)$ & 0.234 & 0.130 & NS & & \\
\hline $\mathrm{SE}(\mathrm{m} \pm)$ & 0.036 & 0.021 & 0.1420 & & \\
\hline C.V. & 7.769 & 3.612 & 17.354 & & \\
\hline \multicolumn{6}{|l|}{ Wheat } \\
\hline $\mathrm{T}_{1}$ - Control (No chlorpyrifos) & 0.250 & 0.215 & 0.410 & 0.875 & 0.292 \\
\hline $\mathrm{T}_{2^{-}}-0.25 \%$ (low) & 0.210 & 0.280 & 0.405 & 0.895 & 0.298 \\
\hline $\mathrm{T}_{3}-0.75 \%$ (medium) & 0.230 & 0.250 & 0.380 & 0.860 & 0.287 \\
\hline $\mathrm{T}_{4^{-}} 1.25 \%$ (High) & 0.190 & 0.185 & 0.360 & 0.735 & 0.245 \\
\hline Mean & 0.220 & 0.233 & 0.389 & & \\
\hline $\mathrm{CD}(\mathrm{P}=0.05)$ & 0.040 & 0.032 & 0.036 & & \\
\hline $\mathrm{CD}(\mathrm{P}=0.01)$ & NS & 0.054 & NS & & \\
\hline $\mathrm{SE}(\mathrm{m} \pm)$ & 0.010 & 0.008 & 0.009 & & \\
\hline C.V. & 6.428 & 4.809 & 3.279 & & \\
\hline
\end{tabular}

DAS (Days after sowing) 
Table.4 Impact of pesticide on stem dry weight $(\mathrm{g})$ of soybean and wheat at various growth phases i.e., 30, 45 and 60 DAS

\begin{tabular}{llllll}
\hline \hline Stem dry wt. (g) & DAS 30 & DAS 45 & DAS 60 & Total & Mean \\
\hline Soybean & & & & & \\
$\mathrm{T}_{1}$ - Control (No chlorpyrifos) & 0.375 & 0.390 & 0.740 & 1.505 & $\mathbf{0 . 5 0 2}$ \\
$\mathrm{T}_{2}-0.25 \%$ (low) & 0.235 & 0.410 & 0.710 & 1.355 & $\mathbf{0 . 4 5 2}$ \\
$\mathrm{T}_{3}-0.75 \%$ (medium) & 0.340 & 0.425 & 0.560 & 1.325 & $\mathbf{0 . 4 4 2}$ \\
$\mathrm{T}_{4}-1.25 \%$ (High) & 0.230 & 0.345 & 0.610 & 1.185 & $\mathbf{0 . 3 9 5}$ \\
\hline Mean & $\mathbf{0 . 2 9 5}$ & $\mathbf{0 . 3 9 3}$ & $\mathbf{0 . 6 5 5}$ & & \\
$\mathrm{CD}(\mathrm{P}=0.05)$ & 0.082 & $\mathrm{NS}$ & 0.103 & & \\
$\mathrm{CD}(\mathrm{P}=0.01)$ & $\mathrm{NS}$ & $\mathrm{NS}$ & $\mathrm{NS}$ & & \\
$\mathrm{SE}(\mathrm{m} \pm)$ & 0.020 & 0.015 & 0.025 & & \\
C.V. & 9.737 & 5.553 & 5.505 & & \\
\hline Wheat & & & & & \\
$\mathrm{T}_{1}-$ Control (No chlorpyrifos) & 0.175 & 0.165 & 0.795 & 1.135 & $\mathbf{0 . 3 7 8}$ \\
$\mathrm{T}_{2}-0.25 \%$ (low) & 0.165 & 0.150 & 0.675 & 0.990 & $\mathbf{0 . 3 3 0}$ \\
$\mathrm{T}_{3}-0.75 \%$ (medium) & 0.135 & 0.145 & 0.460 & 0.740 & $\mathbf{0 . 2 4 7}$ \\
$\mathrm{T}_{4}-1.25 \%$ (High) & 0.130 & 0.120 & 0.760 & 1.010 & $\mathbf{0 . 3 3 7}$ \\
\hline Mean & $\mathbf{0 . 1 5 1}$ & $\mathbf{0 . 1 4 5}$ & $\mathbf{0 . 6 7 3}$ & & \\
CD $(\mathrm{P}=0.05)$ & 0.027 & 0.025 & 0.071 & & \\
CD $(\mathrm{P}=0.01)$ & $\mathrm{NS}$ & NS & 0.111 & & \\
$\mathrm{SE}(\mathrm{m} \pm)$ & 0.007 & 0.006 & 0.018 & & \\
C.V. & 6.185 & 5.973 & 3.718 & & \\
\hline \hline
\end{tabular}

DAS (Days after sowing)

Table.5 Impact of pesticide on root dry weight $(\mathrm{g})$ soybean and wheat at various growth phases i.e., 30, 45 and $60 \mathrm{DAS}$

\begin{tabular}{|c|c|c|c|c|c|}
\hline Root dry wt. (g) & DAS 30 & DAS 45 & DAS 60 & Total & Mean \\
\hline \multicolumn{6}{|l|}{ Soybean } \\
\hline $\mathrm{T}_{1}$ - Control (No chlorpyrifos) & 0.440 & 0.095 & 0.105 & 0.640 & 0.213 \\
\hline $\mathrm{T}_{2^{-}} 0.25 \%$ (low) & 0.155 & 0.125 & 0.110 & 0.390 & 0.130 \\
\hline $\mathrm{T}_{3}-0.75 \%$ (medium) & 0.245 & 0.065 & 0.060 & 0.370 & 0.123 \\
\hline $\mathrm{T}_{4^{-}} 1.25 \%(\mathrm{High})$ & 0.195 & 0.085 & 0.080 & 0.360 & 0.120 \\
\hline Mean & 0.259 & 0.093 & $\mathbf{0 . 0 8 9}$ & & \\
\hline $\mathrm{CD}(\mathrm{P}=0.05)$ & 0.048 & 0.020 & 0.036 & & \\
\hline $\mathrm{CD}(\mathrm{P}=0.01)$ & 0.070 & 0.035 & NS & & \\
\hline $\mathrm{SE}(\mathrm{m} \pm)$ & 0.012 & 0.005 & 0.009 & & \\
\hline C.V. & 6.553 & 7.644 & 14.363 & & \\
\hline \multicolumn{6}{|l|}{ Wheat } \\
\hline $\mathrm{T}_{1}$ - Control (No chlorpyrifos) & 0.135 & 0.146 & 0.345 & 0.626 & 0.209 \\
\hline $\mathrm{T}_{2}-0.25 \%$ (low) & 0.126 & 0.141 & 0.275 & 0.542 & 0.181 \\
\hline $\mathrm{T}_{3^{-}} 0.75 \%$ (medium) & 0.091 & 0.095 & 0.245 & 0.431 & 0.144 \\
\hline $\mathrm{T}_{4}-1.25 \%(\mathrm{High})$ & 0.084 & 0.116 & 0.245 & 0.445 & 0.148 \\
\hline Mean & 0.109 & 0.125 & 0.278 & & \\
\hline $\mathrm{CD}(\mathrm{P}=0.05)$ & 0.011 & 0.006 & 0.053 & & \\
\hline $\mathrm{CD}(\mathrm{P}=0.01)$ & 0.016 & 0.003 & NS & & \\
\hline $\mathrm{SE}(\mathrm{m} \pm)$ & 0.003 & 0.001 & 0.013 & & \\
\hline C.V. & 3.513 & 1.633 & 6.742 & & \\
\hline
\end{tabular}

DAS (Days after sowing) 
Table.6 Impact of pesticide on photosynthesis rate $\left(\mu\right.$ moleCO $\left.\mathrm{C}_{2} / \mathrm{m}^{2} / \mathrm{sec}\right)$ of soybean and wheat at various growth phases i.e., 30, 45 and 60 DAS

\begin{tabular}{llllll}
\hline \hline Photosynthesis rate & DAS 30 & DAS 45 & DAS 60 & Total & Mean \\
\hline Soybean & & & & & \\
$\mathrm{T}_{1^{-} \text {- Control (No chlorpyrifos) }}$ & 7.80 & 9.10 & 8.05 & 24.95 & $\mathbf{8 . 3 2}$ \\
$\mathrm{T}_{2}-0.25 \%$ (low) & 8.20 & 5.90 & 8.35 & 22.45 & $\mathbf{7 . 4 8}$ \\
$\mathrm{T}_{3}-0.75 \%$ (medium) & 7.05 & 4.10 & 9.65 & 20.80 & $\mathbf{6 . 9 3}$ \\
$\mathrm{T}_{4^{-}}-25 \%$ (High) & 4.05 & 3.55 & 4.90 & 12.50 & $\mathbf{4 . 1 7}$ \\
\hline Mean & $\mathbf{6 . 7 8}$ & $\mathbf{5 . 6 6}$ & $\mathbf{7 . 7 4}$ & & \\
$\mathrm{CD}(\mathrm{P}=0.05)$ & 1.00 & 0.86 & 1.30 & & \\
$\mathrm{CD}(\mathrm{P}=0.01)$ & 1.61 & 1.40 & 2.10 & & \\
$\mathrm{SE}(\mathrm{m} \pm)$ & 0.25 & 0.21 & 0.32 & & \\
$\mathrm{C} . \mathrm{V}$. & 5.17 & 5.34 & 5.91 & & \\
\hline \hline Wheat & & & & & \\
$\mathrm{T}_{1}-$ Control (No chlorpyrifos) & 7.85 & 11.15 & 6.60 & 25.60 & $\mathbf{8 . 5 3}$ \\
$\mathrm{T}_{2}-0.25 \%$ (low) & 8.35 & 7.05 & 7.35 & 22.75 & $\mathbf{7 . 5 8}$ \\
$\mathrm{T}_{3}-0.75 \%$ (medium) & 9.40 & 9.95 & 8.50 & 27.85 & $\mathbf{9 . 2 8}$ \\
$\mathrm{T}_{4}-1.25 \%$ (High) & 5.15 & 7.25 & 7.35 & 19.75 & $\mathbf{6 . 5 8}$ \\
\hline Mean & $\mathbf{7 . 6 9}$ & $\mathbf{8 . 8 5}$ & $\mathbf{7 . 4 5}$ & & \\
$\mathrm{CD}(\mathrm{P}=0.05)$ & 1.49 & 1.55 & 0.55 & & \\
$\mathrm{CD}(\mathrm{P}=0.01)$ & $\mathrm{NS}$ & 2.50 & 0.80 & & \\
$\mathrm{SE}(\mathrm{m} \pm)$ & 0.37 & 0.38 & 0.14 & & \\
$\mathrm{C} . \mathrm{V}$. & 6.81 & 6.14 & 2.60 & & \\
\hline \hline
\end{tabular}

DAS (Days after sowing)

Table.7 Impact of pesticide on stomatal conductance $\left(\mu \mathrm{mol} / \mathrm{m}^{2} / \mathrm{sec}\right)$ of soybean and wheat at various growth phases i.e., 30, 45 and 60 DAS

\begin{tabular}{|c|c|c|c|c|c|}
\hline Stomatal conductance & DAS 30 & DAS 45 & DAS 60 & Total & Mean \\
\hline \multicolumn{6}{|l|}{ Soybean } \\
\hline $\mathrm{T}_{1}$ - Control (No chlorpyrifos) & 79.0 & 105.5 & 115.5 & 300.0 & 100.0 \\
\hline $\mathrm{T}_{2}-0.25 \%$ (low) & 98.0 & 116.0 & 116.5 & 330.5 & 110.2 \\
\hline $\mathrm{T}_{3}-0.75 \%$ (medium) & 100.5 & 120.0 & 96.0 & 316.5 & 105.5 \\
\hline $\mathrm{T}_{4^{-}}-1.25 \%(\mathrm{High})$ & 162.5 & 86.0 & 85.5 & 334.0 & 111.3 \\
\hline Mean & 110.0 & 106.9 & 103.4 & & \\
\hline $\mathrm{CD}(\mathrm{P}=0.05)$ & 15.2 & 16.0 & 18.9 & & \\
\hline $\mathrm{CD}(\mathrm{P}=0.01)$ & 24.5 & NS & NS & & \\
\hline $\mathrm{SE}(\mathrm{m} \pm)$ & 3.8 & 4.0 & 4.7 & & \\
\hline C.V. & 4.8 & 5.3 & 6.4 & & \\
\hline \multicolumn{6}{|l|}{ Wheat } \\
\hline $\mathrm{T}_{1^{-}}$Control (No chlorpyrifos) & 2.94 & 3.60 & 2.55 & 9.09 & 3.03 \\
\hline $\mathrm{T}_{2}-0.25 \%$ (low) & 3.02 & 3.40 & 3.50 & 9.92 & 3.31 \\
\hline $\mathrm{T}_{3}-0.75 \%$ (medium) & 2.62 & 3.65 & 3.00 & 9.27 & 3.09 \\
\hline $\mathrm{T}_{4^{-}}-1.25 \%(\mathrm{High})$ & 2.07 & 3.50 & 3.00 & 8.57 & 2.86 \\
\hline Mean & 2.66 & 3.54 & 3.01 & & \\
\hline $\mathrm{CD}(\mathrm{P}=0.05)$ & 0.49 & NS & 0.58 & & \\
\hline $\mathrm{CD}(\mathrm{P}=0.01)$ & NS & NS & NS & & \\
\hline $\mathrm{SE}(\mathrm{m} \pm)$ & 0.12 & 0.14 & 0.14 & & \\
\hline C.V. & 6.39 & 5.74 & 6.74 & & \\
\hline
\end{tabular}

DAS (Days after sowing) 
Table.8 Impact of pesticide on transpiration rate $\left(\mu \mathrm{mol} \mathrm{H}_{2} \mathrm{O} / \mathrm{m}^{2} / \mathrm{sec}\right)$ of soybean and wheat at various growth phases i.e., 30, 45 and 60 DAS

\begin{tabular}{llllll}
\hline \hline Transpiration rate & DAS 30 & DAS 45 & DAS 60 & Total & Mean \\
\hline Soybean & & & & & \\
$\mathrm{T}_{1}$ - Control (No chlorpyrifos) & 2.81 & 2.60 & 2.94 & 8.35 & $\mathbf{2 . 7 8}$ \\
$\mathrm{T}_{2}-0.25 \%$ (low) & 3.50 & 2.93 & 3.02 & 9.45 & $\mathbf{3 . 1 5}$ \\
$\mathrm{T}_{3}-0.75 \%$ (medium) & 3.60 & 3.15 & 2.62 & 9.36 & $\mathbf{3 . 1 2}$ \\
$\mathrm{T}_{4}-1.25 \%$ (High) & 5.17 & 2.59 & 2.26 & 10.01 & $\mathbf{3 . 3 4}$ \\
\hline Mean & $\mathbf{3 . 7 7}$ & $\mathbf{2 . 8 2}$ & $\mathbf{2 . 7 1}$ & & \\
$\mathrm{CD}(\mathrm{P}=0.05)$ & 0.54 & $\mathrm{NS}$ & 0.42 & & \\
$\mathrm{CD}(\mathrm{P}=0.01)$ & 0.87 & $\mathrm{NS}$ & $\mathrm{NS}$ & & \\
$\mathrm{SE}(\mathrm{m} \pm)$ & 0.13 & 0.40 & 0.11 & & \\
$\mathrm{C} . \mathrm{V}$. & 5.01 & 20.06 & 5.48 & & \\
\hline Wheat & & & & & \\
$\mathrm{T}_{1}-$ Control (No chlorpyrifos) & 2.94 & 3.60 & 2.55 & 9.09 & $\mathbf{3 . 0 3}$ \\
$\mathrm{T}_{2}-0.25 \%$ (low) & 3.02 & 3.40 & 3.50 & 9.92 & $\mathbf{3 . 3 1}$ \\
$\mathrm{T}_{3}-0.75 \%$ (medium) & 2.62 & 3.65 & 3.00 & 9.27 & $\mathbf{3 . 0 9}$ \\
$\mathrm{T}_{4}-1.25 \%$ (High) & 2.07 & 3.50 & 3.00 & 8.57 & $\mathbf{2 . 8 6}$ \\
\hline Mean & $\mathbf{2 . 6 6}$ & $\mathbf{3 . 5 4}$ & $\mathbf{3 . 0 1}$ & & \\
$\mathrm{CD}(\mathrm{P}=0.05)$ & 0.49 & $\mathrm{NS}$ & 0.58 & & \\
$\mathrm{CD}(\mathrm{P}=0.01)$ & $\mathrm{NS}$ & $\mathrm{NS}$ & $\mathrm{NS}$ & & \\
$\mathrm{SE}(\mathrm{m} \pm)$ & 0.12 & 0.14 & 0.14 & & \\
C.V. & 6.39 & 5.74 & 6.74 & & \\
\hline \hline
\end{tabular}

DAS (Days after sowing)

Table.9 Impact of pesticide on peroxidase activity $\left(\Delta O D \mu\right.$ gprotein $\left.{ }^{-1} \mathrm{~min}^{-1}\right)$ in soybean and wheat at various growth phases i.e., 30, 45 and 60 DAS

\begin{tabular}{lccccc}
\hline \hline POXunit/gm & DAS 30 & DAS 45 & DAS 60 & Total & Mean \\
\hline Soybean & & & & & \\
T1- Control (No chlorpyrifos) & 122.4 & 47.55 & 108.4 & 278.35 & 92.78 \\
T2- 0.25\%(low) & 102.75 & 66.35 & 86.05 & 255.15 & 85.05 \\
T3- 0.75\% (medium) & 72.1 & 79.2 & 71.85 & 223.15 & 74.38 \\
T4- $1.25 \%$ (High) & 65.5 & 88.25 & 60.1 & 213.85 & 71.28 \\
\hline Mean & $\mathbf{9 0 . 6 9}$ & $\mathbf{7 0 . 3 4}$ & $\mathbf{8 1 . 6 0}$ & & \\
CD $(\mathrm{P}=0.05)$ & 19.898 & 18.765 & 16.215 & & \\
CD $(\mathrm{P}=0.01)$ & 32.13 & $\mathrm{NS}$ & 26.18 & & \\
SE(m \pm ) & 4.935 & 4.655 & 4.022 & & \\
C.V. & 7.696 & 9.358 & 6.97 & & \\
\hline Wheat & & & & & \\
T1- Control (No chlorpyrifos) & 103.07 & 117.175 & 143.565 & 363.81 & 121.27 \\
T2- 0.25\%(low) & 103.76 & 137.445 & 122.145 & 363.35 & 121.12 \\
T3- $0.75 \%$ (medium) & 89.455 & 142.29 & 146.37 & 378.115 & 126.04 \\
T4- $1.25 \%$ (High) & 134.64 & 148.92 & 140.76 & 424.32 & 141.44 \\
\hline Mean & $\mathbf{1 0 7 . 7 3}$ & $\mathbf{1 3 6 . 4 6}$ & $\mathbf{1 3 8 . 2 1}$ & & \\
CD $(\mathrm{P}=0.05)$ & 21.125 & 16.13 & 13.773 & & \\
CD $(\mathrm{P}=0.01)$ & $\mathrm{NS}$ & $\mathrm{NS}$ & $\mathrm{NS}$ & & \\
SE(m \pm C.V. & 5.24 & 4.001 & 3.416 & & \\
\hline \hline
\end{tabular}

DAS (Days after sowing) 
Table.10 Impact of pesticide on polyphenol oxidase $\left(\mu \mathrm{gProtein}{ }^{-1} \mathrm{~min}^{-1}\right)$ in soybean and wheat at various growth phases i.e., 30, 45 and 60 DAS

\begin{tabular}{|c|c|c|c|c|c|}
\hline Polyphenol oxidase $\left(\mu \mathrm{g}\right.$ Protein $\left.{ }^{-1} \min ^{-1}\right)$ & DAS 30 & DAS 45 & DAS 60 & Total & Mean \\
\hline \multicolumn{6}{|l|}{ Soyabean } \\
\hline $\mathrm{T}_{1}$ - Control (No chlorpyrifos) & 0.0241 & 0.0311 & 0.0289 & 0.0841 & 0.0280 \\
\hline $\mathrm{T}_{2^{-}}-0.25 \%$ (low) & 0.0204 & 0.0301 & 0.0304 & 0.0809 & 0.0270 \\
\hline $\mathrm{T}_{3^{-}} 0.75 \%$ (medium) & 0.0266 & 0.0288 & 0.0295 & 0.0849 & 0.0283 \\
\hline $\mathrm{T}_{4^{-}}-1.25 \%(\mathrm{High})$ & 0.0193 & 0.0328 & 0.0253 & 0.0774 & $\mathbf{0 . 0 2 5 8}$ \\
\hline Mean & 0.0226 & 0.0307 & 0.0285 & & \\
\hline $\mathrm{CD}(\mathrm{P}=0.05)$ & 0.0040 & 0.0020 & 0.0030 & & \\
\hline $\mathrm{CD}(\mathrm{P}=0.01)$ & NS & NS & NS & & \\
\hline $\mathrm{SE}(\mathrm{m} \pm)$ & 0.0010 & 0.0010 & 0.0010 & & \\
\hline C.V. & 7.4940 & 2.8400 & 4.1330 & & \\
\hline \multicolumn{6}{|l|}{ Wheat } \\
\hline $\mathrm{T}_{1}$ - Control (No chlorpyrifos) & 0.0096 & 0.0162 & 0.0102 & 0.0359 & 0.0120 \\
\hline $\mathrm{T}_{2}-0.25 \%$ (low) & 0.0114 & 0.0155 & 0.0116 & 0.0385 & 0.0128 \\
\hline $\mathrm{T}_{3}-0.75 \%$ (medium) & 0.0079 & 0.0129 & 0.0152 & 0.0360 & 0.0120 \\
\hline $\mathrm{T}_{4}-1.25 \%(\mathrm{High})$ & 0.0102 & 0.0134 & 0.0129 & 0.0365 & 0.0122 \\
\hline Mean & 0.0098 & 0.0145 & 0.0124 & & \\
\hline $\mathrm{CD}(\mathrm{P}=0.05)$ & 0.0008 & 0.0007 & 0.0010 & & \\
\hline $\mathrm{CD}(\mathrm{P}=0.01)$ & NS & 0.0002 & 0.0006 & & \\
\hline $\mathrm{SE}(\mathrm{m} \pm)$ & 0.0002 & 0.0002 & 0.0003 & & \\
\hline C.V. & 2.9417 & 1.8162 & 2.9763 & & \\
\hline
\end{tabular}

DAS (Days after sowing)

Table.11 Impact of pesticide on nitrate reductase $\left(\mu \mathrm{gNO}_{2} / \mathrm{g}\right.$ fw/h) in soybean and wheat at various growth phases i.e., 30, 45 and 60 DAS

\begin{tabular}{|c|c|c|c|c|c|}
\hline Nitrate reductase $\left(\mu \mathrm{g} \mathrm{NO}_{2} / \mathrm{g} \mathrm{fw} / \mathrm{h}\right)$ & DAS 30 & DAS 45 & DAS 60 & Total & Mean \\
\hline \multicolumn{6}{|l|}{ Soyabean } \\
\hline $\mathrm{T}_{1}$ - Control (No chlorpyrifos) & 0.0946 & 0.0661 & 0.0180 & 0.1786 & 0.0595 \\
\hline $\mathrm{T}_{2^{-}}-0.25 \%$ (low) & 0.0528 & 0.0734 & 0.0719 & 0.1981 & 0.0660 \\
\hline $\mathrm{T}_{3}-0.75 \%$ (medium) & 0.0731 & 0.0601 & 0.0267 & 0.1599 & 0.0533 \\
\hline $\mathrm{T}_{4^{-}}-1.25 \%(\mathrm{High})$ & 0.1390 & 0.0198 & 0.0663 & 0.2251 & 0.0750 \\
\hline Mean & 0.0899 & 0.0548 & 0.0457 & & \\
\hline $\mathrm{CD}(\mathrm{P}=0.05)$ & 0.0010 & 0.0008 & 0.0011 & & \\
\hline $\mathrm{CD}(\mathrm{P}=0.01)$ & 0.0060 & 0.0060 & 0.0060 & & \\
\hline $\mathrm{SE}(\mathrm{m} \pm)$ & 0.0003 & 0.0002 & 0.0003 & & \\
\hline C.V. & 0.4123 & 0.5055 & 0.8626 & & \\
\hline \multicolumn{6}{|l|}{ Wheat } \\
\hline $\mathrm{T}_{1}$ - Control (No chlorpyrifos) & 0.0096 & 0.0162 & 0.0102 & 0.0359 & 0.0120 \\
\hline $\mathrm{T}_{2^{-}}-0.25 \%$ (low) & 0.0114 & 0.0155 & 0.0116 & 0.0385 & 0.0128 \\
\hline $\mathrm{T}_{3}-0.75 \%$ (medium) & 0.0079 & 0.0129 & 0.0152 & 0.0360 & 0.0120 \\
\hline $\mathrm{T}_{4^{-}}-1.25 \%($ High $)$ & 0.0102 & 0.0134 & 0.0129 & 0.0365 & 0.0122 \\
\hline Mean & 0.0098 & 0.0054 & 0.0054 & & \\
\hline $\mathrm{CD}(\mathrm{P}=0.05)$ & 0.0008 & 0.0007 & 0.0010 & & \\
\hline $\mathrm{CD}(\mathrm{P}=0.01)$ & NS & 0.0030 & 0.0060 & & \\
\hline $\mathrm{SE}(\mathrm{m} \pm)$ & 0.0002 & 0.0002 & 0.0003 & & \\
\hline C.V. & 2.9417 & 1.8162 & 2.9763 & & \\
\hline
\end{tabular}

DAS (Days after sowing) 
Table.12 Impact of pesticide on proline content $(\mu \mathrm{mole} / \mathrm{g})$ in soybean and wheat at various growth phases i.e., 30, 45 and 60 DAS

\begin{tabular}{|c|c|c|c|c|c|}
\hline Proline $(\mu \mathrm{mole} / \mathrm{g})$ & DAS 30 & DAS 45 & DAS 60 & Total & Mean \\
\hline \multicolumn{6}{|l|}{ Soybean } \\
\hline $\mathrm{T}_{1}$-Control (No chlorpyrifos) & 0.0160 & 0.0250 & 0.0170 & 0.0580 & 0.0193 \\
\hline $\mathrm{T}_{2}-0.25 \%$ (low) & 0.0160 & 0.0210 & 0.0200 & 0.0570 & 0.0190 \\
\hline $\mathrm{T}_{3}-0.75 \%$ (medium) & 0.0150 & 0.0190 & 0.0220 & 0.0560 & 0.0187 \\
\hline $\mathrm{T}_{4^{-}} 1.25 \%(\mathrm{High})$ & 0.0150 & 0.0190 & 0.0230 & 0.0570 & 0.0190 \\
\hline Mean & 0.0155 & 0.0210 & 0.0205 & & \\
\hline $\mathrm{CD}(\mathrm{P}=0.05)$ & 0.0010 & 0.0010 & 0.0010 & & \\
\hline $\mathrm{CD}(\mathrm{P}=0.01)$ & 0.0010 & 0.0080 & 0.0040 & & \\
\hline $\mathrm{SE}(\mathrm{m} \pm)$ & 0.0000 & 0.0000 & 0.0000 & & \\
\hline C.V. & 1.6140 & 0.8890 & 1.5110 & & \\
\hline \multicolumn{6}{|l|}{ Wheat } \\
\hline $\mathrm{T}_{1}$-Control (No chlorpyrifos) & 0.1200 & 0.0060 & 0.0070 & 0.1330 & 0.0443 \\
\hline $\mathrm{T}_{2^{-}} 0.25 \%$ (low) & 0.3250 & 0.0100 & 0.0100 & 0.3450 & 0.1150 \\
\hline $\mathrm{T}_{3}-0.75 \%$ (medium) & 0.0300 & 0.0090 & 0.0090 & 0.0480 & 0.0160 \\
\hline $\mathrm{T}_{4^{-}} 1.25 \%(\mathrm{High})$ & 0.0450 & 0.0090 & 0.0090 & 0.0630 & 0.0210 \\
\hline Mean & 0.1300 & 0.0085 & 0.0088 & & \\
\hline $\mathrm{CD}(\mathrm{P}=0.05)$ & 0.0140 & 0.0010 & 0.0020 & & \\
\hline $\mathrm{CD}(\mathrm{P}=0.01)$ & 0.0200 & 0.0030 & NS & & \\
\hline $\mathrm{SE}(\mathrm{m} \pm)$ & 0.0040 & 0.0000 & 0.0000 & & \\
\hline C.V. & 3.8470 & 6.0610 & 7.3120 & & \\
\hline
\end{tabular}

DAS $\overline{\text { (Days after sowing) }}$

Table.13 Impact of pesticide on total soluble protein $(\mathrm{mg} / \mathrm{g} \mathrm{fw})$ in soybean and wheat at various growth phases i.e., 30, 45 and 60 DAS

\begin{tabular}{llllll}
\hline \hline TSP $(\mathrm{mg} / \mathrm{gm} \mathrm{fw})$ & DAS 30 & DAS 45 & DAS 60 & Total & Mean \\
\hline Soybean & & & & & \\
$\mathrm{T}_{1}$ - Control (No chlorpyrifos) & 1.750 & 1.450 & 1.680 & 4.880 & $\mathbf{1 . 6 2 7}$ \\
$\mathrm{T}_{2}-0.25 \%$ (low) & 1.595 & 1.360 & 1.575 & 4.530 & $\mathbf{1 . 5 1 0}$ \\
$\mathrm{T}_{3}-0.75 \%$ (medium) & 1.645 & 1.540 & 1.680 & 4.865 & $\mathbf{1 . 6 2 2}$ \\
$\mathrm{T}_{4}-1.25 \%$ (High) & 1.545 & 1.355 & 1.910 & 4.810 & $\mathbf{1 . 6 0 3}$ \\
\hline Mean & $\mathbf{1 . 6 3 4}$ & $\mathbf{1 . 4 2 6}$ & $\mathbf{1 . 7 1 1}$ & & \\
$\mathrm{CD}(\mathrm{P}=0.05)$ & 0.117 & 0.046 & 0.058 & & \\
$\mathrm{CD}(\mathrm{P}=0.01)$ & $\mathrm{NS}$ & 0.075 & 0.095 & & \\
$\mathrm{SE}(\mathrm{m} \pm)$ & 0.029 & 0.011 & 0.014 & & \\
$\mathrm{C} . \mathrm{V}$. & 2.514 & 1.136 & 1.186 & & \\
\hline Wheat & & & & & \\
$\mathrm{T}_{1}-$ Control (No chlorpyrifos) & 1.680 & 1.720 & 1.430 & 4.830 & 1.610 \\
$\mathrm{~T}_{2}-0.25 \%$ (low) & 1.740 & 1.675 & 1.485 & 4.900 & 1.633 \\
$\mathrm{~T}_{3}-0.75 \%$ (medium) & 1.645 & 1.780 & 1.530 & 4.955 & 1.652 \\
$\mathrm{~T}_{4}-1.25 \%$ (High) & 1.755 & 1.735 & 1.630 & 5.120 & 1.707 \\
\hline $\mathrm{Mean}$ & $\mathbf{1 . 7 0 5}$ & $\mathbf{1 . 7 2 8}$ & $\mathbf{1 . 5 1 9}$ & & \\
$\mathrm{CD}(\mathrm{P}=0.05)$ & 0.051 & 0.062 & 0.076 & & \\
$\mathrm{CD}(\mathrm{P}=0.01)$ & $\mathrm{NS}$ & $\mathrm{NS}$ & 0.128 & & \\
$\mathrm{SE}(\mathrm{m} \pm)$ & 0.013 & 0.015 & 0.019 & & \\
$\mathrm{C} . \mathrm{V}$. & 1.057 & 1.262 & 1.758 & & \\
\hline \hline
\end{tabular}

DAS (Days after sowing) 
Table.14 Impact of pesticide on non structral carbohydrate $(\mathrm{mg} / \mathrm{g})$ in soybean and wheat at various growth phases i.e., 30, 45 and 60 DAS

\begin{tabular}{lccccc}
\hline \hline $\begin{array}{l}\text { Non structral } \\
\text { carbohydrate(mg/g) }\end{array}$ & $\begin{array}{c}\text { DAS } \\
\mathbf{3 0}\end{array}$ & $\begin{array}{c}\text { DAS } \\
\mathbf{4 5}\end{array}$ & $\begin{array}{c}\text { DAS } \\
\mathbf{6 0}\end{array}$ & Total & Mean \\
\hline Soybean & & & & & \\
$\mathrm{T}_{1}$-Control(No chlorpyrifos) & 2.931 & 7.615 & 11.006 & 21.553 & $\mathbf{7 . 1 8 4}$ \\
$\mathrm{T}_{2}-0.25 \%($ low) & 3.474 & 9.144 & 12.513 & 25.130 & $\mathbf{8 . 3 7 7}$ \\
$\mathrm{T}_{3}-0.75 \%$ (medium) & 3.063 & 7.508 & 10.271 & 20.841 & $\mathbf{6 . 9 4 7}$ \\
$\mathrm{T}_{4}-1.25 \%$ (High) & 3.190 & 6.906 & 8.963 & 19.059 & $\mathbf{6 . 3 5 3}$ \\
\hline Mean & $\mathbf{3 . 1 6 4}$ & $\mathbf{7 . 7 9 3}$ & $\mathbf{1 0 . 6 8 8}$ & & \\
$\mathrm{CD}(\mathrm{P}=0.05)$ & 0.081 & 0.737 & 0.325 & & \\
$\mathrm{CD}(\mathrm{P}=0.01)$ & 0.136 & 1.220 & 0.530 & & \\
$\mathrm{SE}(\mathrm{m} \pm)$ & 0.021 & 0.188 & 0.083 & & \\
$\mathrm{C} . \mathrm{V}$. & 0.920 & 3.404 & 1.094 & & \\
\hline Wheat & & & & & \\
$\mathrm{T}_{1}-\mathrm{Control}(\mathrm{No}$ chlorpyrifos) & 3.275 & 5.719 & 5.719 & 14.713 & $\mathbf{4 . 9 0 4}$ \\
$\mathrm{T}_{2}-0.25 \%($ low) & 4.550 & 10.250 & 10.250 & 25.050 & $\mathbf{8 . 3 5 0}$ \\
$\mathrm{T}_{3}-0.75 \%$ (medium) & 3.775 & 6.463 & 6.463 & 16.700 & $\mathbf{5 . 5 6 7}$ \\
$\mathrm{T}_{4}-1.25 \%$ (High) & 2.571 & 4.975 & 4.975 & 12.521 & $\mathbf{4 . 1 7 4}$ \\
\hline Mean & $\mathbf{3 . 5 4 3}$ & $\mathbf{6 . 8 5 2}$ & $\mathbf{6 . 8 5 2}$ & & \\
$\mathrm{CD}(\mathrm{P}=0.05)$ & 0.404 & 0.911 & 1.031 & & \\
$\mathrm{CD}(\mathrm{P}=0.01)$ & 0.668 & 1.510 & 1.700 & & \\
$\mathrm{SE}(\mathrm{m} \pm)$ & 0.103 & 0.232 & 0.263 & & \\
$\mathrm{C} . \mathrm{V}$. & 4.108 & 4.788 & 4.059 & & \\
\hline \hline
\end{tabular}

DAS (Days after sowing)

Treatments

\begin{tabular}{ll}
\hline Treatments & Treatment details \\
\hline $\mathbf{T}_{\mathbf{1}}$ & Control (No chloropyrifos) \\
$\mathbf{T}_{\mathbf{2}}$ & Foliar application below normal (Low) $-0.25 \%$ \\
$\mathbf{T}_{\mathbf{3}}$ & Foliar application recommended dose (Medium)-0.75\% \\
$\mathbf{T}_{\mathbf{4}}$ & Foliar application supra-optimal dose (High) $-1.25 \%$
\end{tabular}

$\mathrm{T}_{1-}$ Control (no pesticide use)

$\mathrm{T}_{2}-$ The spray solution is prepared from stock solution. Take $0.25 \mathrm{ml}$ of stock solution and make up the volume $100 \mathrm{ml}$. So $0.25 \%$ low chloropyrifos.

$\mathrm{T}_{3^{-}}$The spray solution is prepared from stock solution. Take $0.75 \mathrm{ml}$ of stock solution and make up the volume $100 \mathrm{ml}$. So $0.75 \%$ medium chloropyrifos.

$\mathrm{T}_{4}$ - The spray solution is prepared from stock solution. Take $1.25 \mathrm{ml}$ of stock solution and make up the volume $100 \mathrm{ml}$. So $1.25 \%$ high chloropyrifos. 

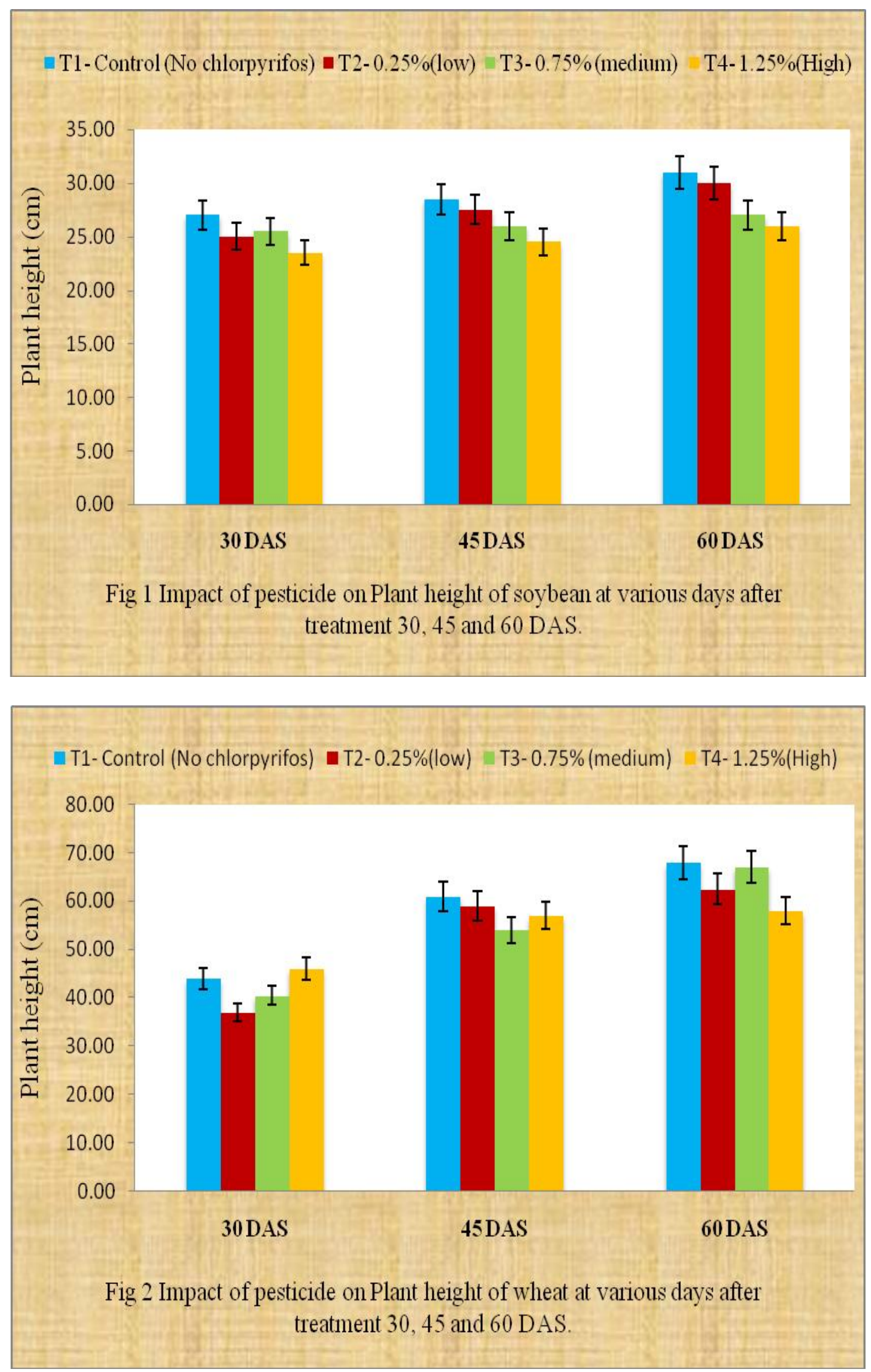

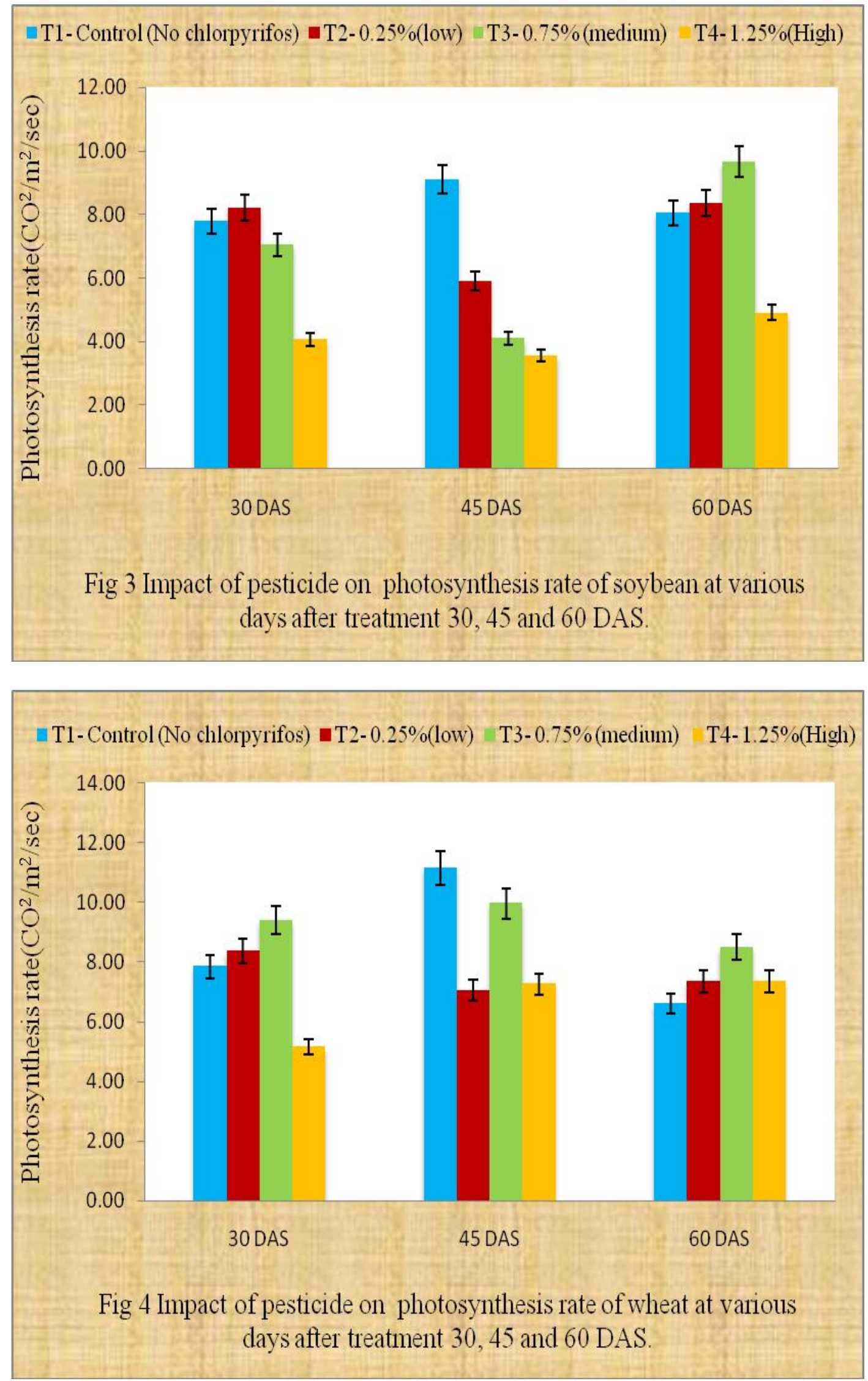


\section{Transpiration rate $\left(\mu \mathrm{mol} \mathrm{H}_{2} \mathrm{O} / \mathrm{m}^{2} / \mathrm{sec}\right)$}

The transpiration rate was measured in $3^{\text {rd }}$ fully expended leaves from the top. The rate was highest in higher concentration and decreased in control. The mean value was greater in $\mathrm{T}_{4} 1.25 \%$ (3.34) in soybean. Whereas in wheat the average value of transpiration rate was highest at $\mathrm{T}_{2} 0.25 \%$ of chlorpyrifos (3.31) followed by $\mathrm{T}_{3} \quad 0.75 \%$ (3.09) and at control (3.03) and minimum rate of transpiration was observed at lower concentration of chlorpyrifos $\mathrm{T}_{4} 1.25 \%$ (2.86) (Table 8). Transpiration is directly related to stomatal opening, which is essential for leaf intake of carbon dioxide for photosynthesis. Photosynthesis is a more general measurement of carbon dioxide intake and fixation (sugar production). Both processes are interrelated and are directly related to plant growth and productivity.

The higher value of transpiration occurred on insecticide-free plants. Photosynthesis was also higher in the untreated check, suggesting that all insecticide treatments adversely influenced both stomatal opening and over all photosynthesis rates as reported by Sances $e t$ al., (1981) similar result were reported by Olszewski. (2004) observed a tendency towards a slight decrease in the rate of photosynthesis under the influence of a fungicidal agent in horse bean and pea. Further, the same author found a significant decline in the levels of photosynthesis and transpiration under the effect of foliar herbicide application. Panduranga et al., (2005) also confirmed the dimethoate causes a reduction in plant growth, photosynthesis pigments and photosynthetic activity of Glycine max L.

\section{Peroxidase ( $\triangle O \mathrm{OD} \mu \mathrm{g}$ protein $\left.{ }^{-1} \mathrm{~min}^{-1}\right)$}

The peroxidase activity was measured at 30 , 45 and 60 DAS in soybean and wheat, and 30,
45 and 60 DAT in ashwagandha. The average rate was decreased with increasing level of pesticide treatment in soybean. However, in wheat it was maximum at $\mathrm{T}_{4}(1.25 \%)$ (141.44). While in ashwagandha it was minimum at $\mathrm{T}_{4}$ (87.64) over control 118.07. However, the enzyme activity was maximum at initial stage of growth and decreased with the passage of time. This might be due to the presence of healthy and efficient $\mathrm{H}_{2} \mathrm{O}_{2}$ scavenging system during the young stage of plant (Table 9).

The result of present investigation suggest that activity of catalase was gradually decreased in treated plants as compared to control which was similar finding reported by Vidyasagar et al., (2007) in Sorghum bicolor L. However, the activity of other oxidative enzymes such as, polyphenol oxidase and peroxidase was increased along with the concentration of chlorpyrifos increased. The increase in peroxidase activity may be due to the metabolic response to environmental stress reported by Fang and Kao (2000). Lee (2002) also reported that the peroxidase activity increased remarkably with $\mathrm{Na}_{2} \mathrm{SO}_{3}$ treatments. Since peroxidase activity was very high in treated shoots, accumulated $\mathrm{H}_{2} \mathrm{O}_{2}$ was utilized for various peroxidative polymerization reactions.

\section{Polyphenol oxidase ( $\mu$ g Protein $\left.{ }^{-1} \mathrm{~min}^{-1}\right)$}

Polyphenol oxidase was measured during the pesticide treatment in soybean and wheat at 30, 45 and 60 DAS and in ashwagandha at 30, 45 and 60 DAT. The content was increased with passage of time in soybean and wheat. Whereas, in ashwagandha it increased maximum at 45 DAT 0.0173 over control. However, it 0.0071 decreased at 60DAT 0.0017 . However, the increased concentration of pesticide slightly increased the activity of polyphenol oxidase in all the experimental crops (Table 10). 
Fang and Kao (2000) also reported that the activity of oxidative enzymes such as, polyphenol oxidase and peroxidase was increased along with the concentration of chlorpyrifos increased. The increase in peroxidase activity may be due to the metabolic response to environmental stress. Similar results have been obtained by Chauhan et al., (2013) in potato reported by Nanjo et al., (1999).

\section{Nitrate reductase $\left(\mu \mathrm{g} \mathrm{NO}_{2} / \mathrm{g} \mathrm{fw} / \mathrm{h}\right)$}

Nitrate reductase activity was significantly affected by pesticide resistance. However, in general it decreased with passage of time in soybean and wheat. Increased concentration of pesticide has shown the maximum activity of nitrate reductase in soybean and wheat. However, in ashwagandha in general its activity increased with passage of time at 60 DAT it was maximum 0.0081.and increased level of treatment increased the activity i.e., at $\mathrm{T}_{4} 1.25 \%$ it was $0.0076\left(\mu \mathrm{g} \mathrm{NO}_{2} / \mathrm{g} \mathrm{fw} / \mathrm{h}\right)$ over control 0.0075( $\left.\mu \mathrm{g} \mathrm{NO}_{2} / \mathrm{g} \mathrm{fw} / \mathrm{h}\right)$ (Table 11).

Nitrate reductase (NR) activity was seen to decrease with concentration of pesticide increase. A result was well supported by Pankaj et al., (2015) also reported significant decrease in activity with increase in concentration of pesticide in Fenugreek.

\section{Proline content $\left(\mu \mathrm{M} \mathrm{g}^{-1}\right)$}

Proline is the amino acid accumulates under stress situation was measured at 30, 45 and 60 DAS after application of chlorpyrifos in soybean, wheat and ashwagandha. The maximum proline content was observed at 60 DAS. However, the increased rate of chemical slightly increased the proline content at $\mathrm{T}_{2} 0.25 \%$ level in wheat $0.115 \mu \mathrm{m} / \mathrm{g}$ over control $0.0443 \mu \mathrm{m} / \mathrm{g}$. It showed more resistant in wheat as compared to soybean and ashwagandha when the control decreased with increasing level of treatment (Table 12).

The proline content also increased in the present studies due to the chlorpyrifos treatment. Similar finding have also been reported by Nasrabadi et al., (2014) in tomato, Parween et al., (2012) in Vigna radiata L. and Coskun et al., 2015. Proline accumulated in plants under various stress conditions. The accumulation of proline in plant due to drought and temperature stress is also well documented by Gzik (1996). Proline acts as a hydrophobic protectant for enzymes and sub-cellular organelles Lerudulier et al., (1994). This helps the plant to tolerate or adapt to the stress condition. It is evident from these studies that an increase in proline content may serve as a mean of protection of plant tissue against stress.

\section{Total soluble protein $(\mathrm{mg} / \mathrm{g} \mathrm{fw})$}

The average total soluble protein was increased with passage of time in all the experimental crops. The treatment of pesticide increased it gradually and significantly in wheat and ashwagandha with increasing level of treatment. Maximum increase was observed at $\mathrm{T}_{4}(1.25 \%)$ in wheat 1.707 over control 1.610. Whereas, in ashwagandha maximum soluble protein was obtained at $\mathrm{T}_{3}(0.75 \%) 1.713$ over control 1.600 In soybean crops the content decreased at 45 DAS and the maximum content was observed at $\mathrm{T}_{2}(0.25 \%) 1.510$ over control 1.627. This might be due to the maintain of chemical stress at cellular level. It the content decreased it might be used for synthesis of new proteins under stress and its increase showed the resistance mechanism of stress viz. more synthesis of protein (Table 13).

Singh and Tiwari (2003) also found the total protein content in plants decreased with increasing of pesticide concentrations compared to the control plants, respectively. 
Protein content in organisms, an important indicator of reversible and irreversible changes in metabolism, is known to respond to a wide variety of stressor such as natural and xenobiotic. It showed that excessive pesticide reduced protein amount of many plant species Zengin et al., (2007) reported by Vidyasagar et al., (2007).

\section{Non-structural carbohydrate (mg/g)}

Non-structural carbohydrate (total soluble sugar + starch) was estimated at 30, 45 and 60DAS. It was significantly increased with passage of time in all the experimental crops. It might be due to more anabolic reaction at the later phase of growth band carbohydrate were synthesized more efficiently. However, the lower dose $\mathrm{T}_{2} \quad 0.25 \%$ of pesticide increased the maximum structural carbohydrate over control in soybean 8.377 over control 7.184. In wheat 8.350 over control 4.904. Whereas, the further increase in dose of pesticide decreased the structural carbohydrate significant in all the experimental crops. However, in ashwagandha the structural carbohydrate was maximum at control over treatments (Table 14).

Siddiqui et al., (2001) also suggested that the carbohydrate content is rapidly decreased with increase the concentration of chlorpyrifos. A similar result was reported by Bhattacharya et al., (2001) in carbendazim treated rice plants.

Chlorpyrifos is a hazardous and important pollutant of the environment. The EU Directive 2008/105/EC lists it as one of the priority water pollutant. Its presence in mainly detected by chemical but, since biological tests have general in importance in the last few years. Chlorpyrifos effect on several metabolic and stress related parameters i.e., morphological physiological and biochemicals. Therefore, the impact of oxidative stress was evaluated on these crop plants to find out the chemical stress tolerance and resistance mechanism. It was observed that as compared to soybean, wheat was found to be same tolerance against the oxidative stress. However, the ashwagandha was initially affected but later it increased its morphophysiological traits.

\section{References}

Aditya, C.N., Banerjee, H. and Kole, R.K. 1997 An appraisal of pesticide use in Indian agriculture with special reference to their consumption in West Bengal. Sci Cult., 63: 223-228

Bashir, F., Siddiqi T.O., and Mahmooduzzafar, Iqbal. M. 2007a Effect of different concentrations of mancozeb on the morphology and anatomy of Lens culinaris L. Indian J Environ Sci 11: 71-74

Bates, L.S., Waldeen, R.P. and Teare, I.D. 1973. Rapid determination of free proline for water-stress studies. Plant and Soil, 39: 205-207.

Boutin, C., Elmegaard, N. and Kjar, C. 2004 Toxicity testing of fifteen non crop plant species with six herbicides in a green house experiment: implications for risk assessment. Ecotoxicology, 23: 34-369.

Bradford, M.M. 1976. A Rapid and Sensitive Method for the Quantitation of Microgram Quantities of Protein Utilizing the Principle of Protein-Dye Binding Analytical Biochemistr., 72: 248-254.

Chauhan,S. S., Agrawal, A. And Srivastava, A. 2013 Effect of imidacloprid insecticide residue on biochemical parameters in potatoes and its estimation by HPLC. Asi. J. Pharm. Clin. Res., 6 (3): 114-117.

Coskun, Y., Kilic, S. and Duran, R.E. 2015. The effect of the insecticide pyriproyfen on germination, development and growth responses of maize seedlings. Fre. Envi. Bull., 24 (1): 278-284.

Elbashier, M.M. A., Shao, X., Mohmmed, A., Ali, A. A. S and Osman B. H. 2016. Effect of pesticide residues (Sevin) on carrot (Daucus carota L.) and free nitrogen fixers 
(Azotobacter spp). Agril. Sci., 7: 93-99.

Endosulfan in mediating stress responses in (sorghum bicolor L.) Moench. J. Envir. Bio., 30 (2), 217-220.

Fang, W. and Kao C.H. 2000. Enhanced peroxide activity in the leaves in response to excess iron, copper and zinc. Plant Sci., 158 (2): 71-76.

Fujita, S. and Tono, T. 1979. Nippon Nogeikagaku Kaishi (in Japanese). 53: 233 243.

Gzik, A.C. 1996. Accumulation of proline and pattern of alfa amino acids in sugar beet plant in response to osmotic water and salt stress. Environ. Exp. Bot., 36 (3): 29-38.

Howard, P.H. (ed) 1991. Handbook of environmental fate and exposure data for organic chemicals. In: Pesticides, vol III. Lewis Publishers, Chalsea, MI

Iqtidar, A. Khalil, Eric, I. Mercer and Zhi X. Wang 2003. Effect of triazole fungicides on the growth, chloroplast pigments and sterol biosynthesis of maize (Zea mays L.). Pt. Sci., 66 (1): 21-28.

Iqtidar, A. Khalil. and Saleem Khan. 1995. Effect of morpholine systemic fungicide on the chloroplast pigments of wheat and maize. Plant Biosystems, 129 (3): 791- 795.

Kashyap, R. K., Chaudhary, O. P. and Sheoran, I. S. 1994. Effect of insecticides seed treatments on seed viability and vigour of wheat cultivar. Seed Sci. \& Technol., 22: 503-17.

Kashyap, V. and Kumar, M. 2013a. Studies on the effects of chlorpyrifos on germination and photosynthetic pigments in green gram (Vigna radiata $\mathrm{L}$.) at different phenological stages. J. Biol. Chem. Res., 30 (2): 868-874

Kashyap, V. and Kumar, M. 2013b. Studies on the effects of chlorpyrifos on growth and yield in green gram (Vigna radiata L.) at different phenological stages. J. Biol. Chem. Res. 30 (2): 734-740.

Khan, H., Zeb, A., Ali, Z. and Shah, S.M. 2009. Impact of five insecticides on chickpea (Cicer arietinum L.) nodulation, yield and nitrogen fixing rhizospheric bacteria. Soil Environ., 28: 56-59

Khan, S.M. and Kour, G. 2007. Sub acute oral toxicity of chlorpyriphos and protective effect of green tea extract. Pest
Biochem. Physiol., 89: 118-123

Kumar, M. and Kumar, R. 1993. Effect of metasystox on certain physiological and biochemical aspects in Vicia faba. Nat Conserv, 5: 109-110.

Kumar, N.G., Nirmala, P. and Jayappa, A.H. 2010. Effect of various methods of application of insecticides on the incidence of serpentine leaf miner, Liriomyza trifolii (burgess) and other pests in soybean. Karnataka J. Agric. Sci., 23: $130-132$

Lee, M.Y. 2002. Effect of $\mathrm{Na}_{2} \mathrm{SO}_{3}$ on the activities of antioxidant enzymes in geranium seedlings. Phytochem., 59 (2): 493-499. (2002).

Lerudulier, D., Strom, A.M., Dandekar, A.M., Smith, L.T. and Valentine, R.C. 1994. Molecular biology of osmoregulation. Sci., 224 (4): 1064-1068.

Lowry, O.H., Rosebrough, N.J., Farr, A.L. and Randall, R.J. 1951. Protein measurement with the Folin-Phenol reagents. J. Biol. Chem., 193: 265-27.

Luscombe, B.M., Pallett, K.E. Loubiere, P. Millet, J.C. Melgarejo, J. and Vrabel, T.E. 1995. RPA 201772 A novel herbicide for broad leaf and grass weed control in maize and sugar cane. British Crop Protection Council. Brighton Crop Protection Conference: Weeds., 2: 35-42.

Nanjo, T., Kobayashi, M., Yoshiba, Y., Sanada, Y., Wada, K. and Tsukaya, H. 1999. Biological functions of proline in morphogenesis and osmotolerance revealed in antisense transgenic Arabidopsis thaliana. Plant J., 18: 185- 193.

Nasrabadi, M. and Dhumal, K. N. 2014. Effect of chlorpyrifos and malathion on stress and osmolyte parameters in tomato and brinjal. Intern. J. Pharma. Bio. Sci., 2 (11): 778787.

Nasrabadi, M., Ghayal, N. and Dhumal, K.N. Effect of chlorpyrifos and malathion on antioxidant enzymes in tomato and brinjal. Intern. J. Pharma. Bio. Sci., 2(2): 09756299.

Olszewski, J. 2004. The effects of some biotic and abiotic stresses on the rate of photosynthesis and transpiration, yield and health of horse bean and pea. (Rozprawy 
Monografie) 85. Wydawnictwo UWM. Olsztyn (in Polish).

Panduranga, M.G., Mahadeva, P.G. and Sudarshana, M.S. 2005 Toxicity of different imbibitions periods of dimethoate on germination, chlorophyll $\mathrm{a} / \mathrm{b}$, and dry matter of Glycine max (L) Merrill. Cv. 548 KHSB-2, during early seedlings growth. J Physiol Res., 18: 199-201

Pankaj, S.M, and Rohit P.G.2015. Effect of pesticide on nitrate reductase activity in (Trigonella Foenum) i.e., fenugreek. J. Hort. 2: 166 . doi: 10.4172/23760354.1000166.

Parween, T., Jan, S., Mahmooduzzafar., and Fatma, T. 2011. Alteration in nitrogen metabolism and plant growth during different developmental stages of green gram (Vigna radiataL.) in response to chlorpyrifos. Actaphysiol. Plant, 33: 23212328.

Parween, T., Mahomooduzzafar, S. J. and Fatima, T. 2012. Evaluation of oxidative stress in material safety data, (Vigna radiata $\mathrm{L}$.) in response to chlorpyrifos, Int. J. Env. Sci., \& Technol., 9,605-612

Siddiqui, Z.S. 1997. Effect of systemic fungicides on total protein, carbohydrate and phenolic contents of (Solanum melongena) and (Avena sativa) Appl. Ent. Phytopath., 64: $17-22$

Siddiqui, Z.S., Ahmed, S. and Gulzar, S. 1997.
Effect of topsin-m (Methylthiophenate) and bayleton (Triademifon) on seedling growth, biomass, nodulation and phenolic content of sesbaniasesban. Bangl. J. Bot., 26 (2): 127-130.

Singh, R.,Saxena, S.K. and Sharma, V.S.P. 1970. An improved method of raising Citrus root stocks. Punjab Hort. J., 10: 166-171

Tevini, M. and Teramura, A.H. 1989. UV-B effects on terrestrial plants. Photochem. Photobiol., 50: 479-487.

Venkateswara, R. J., Parvati, K., Kavitha, P., Jakka, N.M., Pallela, R. 2005. Effect of chlorpyrifos and monocrotophos on loco motor behavior and acetyl cholinesterase activity of subterranean termites, Odontotermes obesus. Pest Manage Sci., 61: 417-421.

Vidyasagar, G.M., Kotresha, D., Sreenivasa,N. and Karnam, R. 2009. Role of

Xia, X.J., Huang, Y.Y., Wang, L., Huang, L.F., Yu, Y.L. Zhou, Y.H. and Yu, J.Q. 2006. Pesticides-induced depression of photosynthesis was alleviated by 24epibrassinolide pretreatment in (Cucumis sativus L.) Pest. Biochem. Physiol., 86: 4248.

Zengin, F.K. and Kirbag, S. 2007. Effects of copper on chlorophyll, proline, protein and abscisic acid level of sunflower (Helianthus annuus L.) seedlings. J. Envir Bio., 28 (3): 561-566.

\section{How to cite this article:}

Nutan Singh, Pratibha Katiyar and Ajay. 2017. Evaluation of Oxidative Stress on Soybean (Glycine max L. Merrill) and Wheat (Triticum aestivum) Crops in Response to Chlorpyrifos. Int.J.Curr.Microbiol.App.Sci. 6(11): 2045-2064. doi: https://doi.org/10.20546/ijcmas.2017.611.243 